\title{
Research on the Influencing Factors of Returning Home for Employment of Xinjiang Minority College Students Studying in Jiangxi Province
}

\author{
Yuting $\mathrm{Xu}^{1, \mathrm{a}^{*}}$ and Chongkun $\mathrm{Xu} \mathrm{u}^{2, \mathrm{~b}}$ \\ ${ }^{1}$ Nanchang Institute of Science and Technology, Shangrao, Jiangxi \\ ${ }^{2}$ Nanchang Institute of Science and Technology, Nanchang, Jiangxi, 330108, China \\ a121037798@qq.com, buchongkunjx@126.com \\ * The Corresponding Author
}

Keywords: Xinjiang; Minority college students; Returning home for employment; Influence factor

Abstract. The employment ability of minority college students is relatively weak because of the special regional environment, Chinese language ability and weak basic education. It is an urgent problem to study the factors affecting the employment behavior of Xinjiang minority college students studying in Jiangxi Province and take practical solutions. On the basis of previous studies, this paper studies the factors that affect the home returning for employment of Xinjiang minority college students studying in Jiangxi Province, and analyzes them from four aspects: cultural factors, personal factors, policy factors and family backgrounds, which provides new ideas for related research.

\section{Introduction}

Employment, as the core of the people's livelihood and personal dignity, is related to the vital interests of millions of families and the harmony and stability of the society. In recent years, the problem of difficult employment of college students is very prominent and has been widely concerned by the society. In the regions where the minorities live in compact communities, the employment difficulties of minority students are particularly prominent. Although the difficulty of employment is a common phenomenon in the whole society, the employment space of the minority graduates is narrower and the employment scope is concentrated, so the difficulty of employment becomes greater. Due to the characteristics of national culture and their own reasons, the Xinjiang minority college students studying in Jiangxi Province are biased towards returning home for employment, which makes the employment scope narrower and the employment situation more severe. In addition, the minority graduates and their parents are more anxious about the employment problem, so the social harm it brings is undoubtedly serious.

\section{Overseas Research Status}

The research on the rural employment of college students abroad is more biased towards the construction of the employment system in the country. Among them, Germany has been committed to controlling the unemployment rate of young people, and on this basis has established a sound policy and regulation system, a complete employment guidance system and strict vocational training system. In addition, there is a "New Deal for Young People" in the UK. The policy was launched by the British government in 1998, providing employment related help for young people who are unemployed for over 6 months, and young people can make choices based on their actual situation. In addition, some researchers are inclined to dig out the reasons of the employment problems. Most scholars discuss mainly from the perspective of demand, supply and supply and demand matching. They point out that today's college students have obvious tendency in employment, and for individual positions, no one even wants to do it. However, for the job that college students want to do, they are unable to do it because of their own lack of ability and other factors.

The research on employment theory abroad is more abundant. Social capital theory held that the social capital determined the social network resources of individuals in a certain sense, and social 
network resources determined the occupation acquisition of individuals to a certain extent. In addition, Sidherman(1979) believed that various occupational posts had certain requirements for human capital. This amount can be obtained through different combinations of formal education, in-service training and practical experience, which constituted the main factors of human capital, that is more formal school education and less in-service training and experience, or less formal education and more in-service training and experience. Spence's (1984) career screening theory held that the most important function of education is to screen job seekers, so that employers can arrange job seekers with different abilities and skills to different job positions. The professional competition model of Thurpw (1990) was mainly to investigate and discuss the overeducation from the profession. The competition model investigated and discussed the overeducation not only from professional sequence, but also from the individual sequence. Raphael (1992) and other educational economists claimed that career screening models and career competition models were important reasons for overeducation in developing countries, but they were not fundamental reasons. The fundamental reason is that these countries are attached to the social and economic structure of the developed countries. That is to say, only the so-called "dependency theory" can deeply reveal the essence and the root of overeducation in developing countries.

There are few studies on the problem of returning home for employment of college graduates by foreign scholars, and only Terry \& Lawyer(1995) is relevant. Buchanan(2005) understood the attitude of college graduates to agricultural problems through investigation and research. Mahoney (2009) studied the problem of returning home after graduation of American college students.

\section{Domestic Research Status}

Study on the Employment Problem of Xinjiang Minority College Students. In the era of planned economy, our country has always implemented the employment policy of "unified assignment" for college students. Therefore, the employment of college students was "no problem". Since 1995, the employment system of college students in China has been reformed, and the "unified assignment" has been transformed into the employment policy of "independent career selection and two-way choice". Thus the employment became a major problem that college students must pay attention to and solve by themselves. Since 2003, Xinjiang has started a policy of independent career selection for all college students. It is from this year that the problem of employment of Xinjiang minority students has been highlighted. The blue book in 2003 published by the Xinjiang Academy of Social Sciences pointed out that "it is difficult for graduates in Xinjiang to be employed, and the most difficult is the minority graduates". In 2004, the blue book emphasized that "the employment situation of minority graduates is becoming more and more severe". It was also from this period that domestic scholars began to study the employment problem of Xinjiang minority college students.

In the existing research literature, the research on employment problems of Xinjiang minority college students is mainly focused on the causes of employment difficulties and the countermeasures to solve this problem. Xiaokun Chen(2011), with the help of investigation data, found that there were still some problems in minority college graduates, such as low employment rate, low perceptibility of employment pressure and low cognition of employment units, which can be solved by means of government administrative means, the implementation of the combination of the minority and the Han nationality, and the improvement of the employment guarantee mechanism. Baofeng Wang(2013) investigated and found that there were six factors affecting the successful employment of minority college students, such as employment preparation, employment plan, employment concept, employment expectation and employment guidance. So it was necessary to work together in three aspects of society, schools and individuals to solve the problem fundamentally. In addition, there are many studies on the employment of Xinjiang minority college students from the perspective of sociology and pedagogy. The literature of pedagogy generally studies the influence of colleges and universities on the employment of college graduates. Xiaoqing $\mathrm{Hu}(2015)$ proposed countermeasures and suggestions to strengthen the employment education of minority college students from four aspects: innovation on the content of employment education for 
minority college students, the improvement of form and method, the expansion of the way and the transformation of the employment concept of the minority college students themselves.

The sociological literature generally explores the influence of changing social environment on the employment of college students in China (employment pressure). There are also some sociological documents that focus on exploring the the influence of graduates' personal attributes on their employment, such as career psychology, employment expectations and so on. Zhenyu Hu and Lingyun Jin(2013) analyzed the problems of Xinjiang minority college students in mainland China, such as low level of Chinese and English, weak professional and technical ability, lack of comprehensive ability and weak employment and entrepreneurship ability. So we can promote the full employment of minority college students by enhancing the ability of employment and entrepreneurship. Through comparative analysis, Shengnan $\mathrm{Wu}(2015)$ found that there were obvious differences between minority college students and Han college students in employment expectation, employment plan, employment concept and employment preparation, and then found out the causes of there differences from three aspects of society, colleges and minority college students themselves, and put forward some suggestions to promote the employment of college students from the perspective of demand and supply.

There are also some scholars that analyze the supply and demand relationship of the employment of Xinjiang minority college students in China from the economics, especially the labour economics. Nuermanguli Nuermaimaiti(2016) combined the economic development of Southern Xinjiang and the employment of minority college students, and put forward the main measures and policy suggestions to solve the employment problems of minority college students in Southern Xinjiang from a new perspective. A few scholars paid attention to the special groups of Xinjiang minority college graduates - female students, and discussed their employment problems. Gang Li(2016) analyzed the factors influencing the employment of minority female college students in Tarim University from three dimensions of schools, employers and students, and put forward feasible countermeasures to solve the problem of employment of Xinjiang minority female college students. Of course, there were still a few scholars that deeply studied the employment problem of Xinjiang minority college students from the employment related policies and the role played by the government in employment.

Research on the Problem of Returning Home for Employment of College Graduates. Most of the research on returning home for employment of college students is to analyze the problem of returning home for employment, find out the reasons and give the solutions. Mingfen Zheng and Wenjuan Wu(2010), taking Shishi City of Fujian Province as an example, inspected the characteristics and problems of the employment and entrepreneurship of the college students returning home. They put forward the principle of "three combinations" and the path choice of "complementary advantages of three parties and multiple operation mechanism". In addition, many scholars carried out a related research around the home-returning for employment, such as the willingness of returning home for employment, influencing factors, path, feasibility, policy, government duty, college education and college duty. Even some scholars combined the home-returning for employment and entrepreneurship to get a lot of useful conclusions. Xiaofei Xue(2015) pointed out that through reforming the system and designing the reasonable and feasible incentive assessment mechanism, the willingness of rural students to return home for employment can be improved. Jie Chen(2016) pointed out that through improving national policies, strengthening the enforcement and improving rural environment and equipment conditions, the predicament of rural college students returning home for employment and entrepreneurship can be solved, so as to effectively promote college students to return home and start businesses.

\section{The Influencing Factors of Returning Home for Employment of Xinjiang Minority College Students Studying in Jiangxi Province}

Cultural Factors. Influenced by religious beliefs, customs, traditional concepts and other cultural factors, minority college students consider more about future dietetic life, spouse selection, family care and other factors in the choice of employment area and space. For this reason, the majority of 
college students in Xinjiang universities choose to stay in Xinjiang after graduation, and even some of them only choose to work in their hometown. For Xinjiang minority graduates in Han nationality area, in order to avoid competition with the Han nationality college graduates with obvious advantages, they generally choose to return to Xinjiang for employment. This makes Xinjiang minority college students who study in Han nationality area join in the job hunting team of Xinjiang college graduates, which leads to a large demand for employment in Xinjiang.

Personal Factors. The final result of returning home for employment is to settle down at home. It is very important for everyone to stay in home and work for a lifetime, so the personal factors are very important. At the same time, the personal factor is the inner key factor, and any external factor should reflect the result through the internal function of personal factors. If the city and job do not conform to the personal concept, hobbies and interests, development potential and life pursuit, even though they are good, they can not attract people and retain people. Through the previous analysis, the Xinjiang minority students studying in Jiangxi Province are more inclined to return to their home for employment.

Policy Factors. The employment policy of the government directly affects the employment environment of college students. In recent years, the introduction of multi-level and milti-angle employment promotion policy by state and Xinjiang has not only improved the employment environment, but also provided more opportunities for college students to choose jobs. The comprehensive understanding of college students for employment policy will play a very important role in promoting the employment of college students. From the preliminary survey data, Xinjiang minority college students generally have a better understanding of the employment policies of the state and Xinjiang, which makes the Xinjiang minority college students studying in Jiangxi Province prefer to return home for employment.

Family Background. Xinjiang minority college students studying in Jiangxi Province have been living in closed ethnic areas where religious cultural customs prevail. Their living habits are obviously influenced by religious taboos, which leads to an ambivalence in their employment. On the one hand, they want to go out of the rural and pastoral areas with harsh natural conditions, inconvenient transportation, backward education, culture, and medical treatment, and find a job in medium or large cities. On the other hand, because of the maladjustment of diet, language and living habits, especially the influence of family traditional education, their employment choices are narrow, and they are difficult to integrate into the eastern region of China with the fastest economic development, high marketization degree, high demand for talents and the high potential to absorb the college students. In addition, due to the influence of national traditional culture, Xinjiang minority college students are more affected by their parents than the mainland students on the employment problem. In many places, especially in the southern Xinjiang, parents are more conservative in their thinking, and they have a strong dependence on the government and have a relatively heavy local concept.

\section{References}

[1] O'Higgins, Niall. The Challenge of Youth Unemployment[J], International Social Security Review, 2005, 50(4):63-93.

[2] Lin N, Ensel W M, Vaughn J C. Social Resources and Strength of Ties: Structural Factors in Occupational Status Attainment[J]. American Sociological Review, 1981, 46(4):393-405.

[3] Buchanan, Tom, Johnson, et al. "Implementing a five-factor personality inventory for use on the internet": Erratum.[J], European Journal of Psychological Assessment, 2005, 21(2):448 participants.

[4] Mahoney J, Thelen K. Explaining Institutional Change[M]. Cambridge University Press, 2009.

[5] X.K.Chen: Investigation and Analysis of Employment Status of Minority College Students in Xinjiang[J], Finance and Economics in Xinjiang, 2011(3):70-74.(In Chinese)

[6] B.F.Wang: Analysis of the Employment Dilemma of Minority College Students in Xinjiang and Countermeasure Study [D], Shihezi University, 2013.(In Chinese) 